\title{
CRÍTICAS E ALTERNATIVAS DE WINNICOTT AO CONCEITO DE PULSÃO DE MORTE
}

Leopoldo Fulgencio

Programa de PósGraduação em Psicologia Clínica da PUC-Campinas.
RESUMO: Trata-se de explicitar as críticas que Winnicott fez ao conceito de pulsão de morte, indicando que alternativas ofereceu para resolver os problemas para os quais Freud teria suposto a pulsão de morte. Depois de retomar a posição de Freud, para mostrar que esse conceito serve como uma especulação para compreender a compulsão à repetição, demonstra-se que Winnicott mudou o foco da questão, considerando que os pacientes precisam regredir a situações similares à traumática, anteriores à constituição das defesas contra o trauma, para as integrarem em sua personalidade.

Palavras-chave: Compulsão à repetição, pulsão de morte, metapsicologia, integração, redescrição.

ABSTRACT: Winnicott's criticism and alternatives to the concept of death instinct. The objective of this article is to explain Winnicott's criticism on the concept of death instinct, by showing the alternatives Winnicott gave to solve the problems for which Freud would have supposed the death instinct. After examining Freud's position to show that this concept is used in a speculative way to understand the repetition compulsion, it is shown that Winnicott changed the core of the issue taking into account the fact that patients need to regress to situations similar to the traumatic one, nevertheless, prior to the constitution of the defences against the trauma in order to integrate these traumatic experiences into their personality.

Keywords: Repetition-compulsion, death instinct, metapsychology, integration, redescription. 


\section{INTRODUÇÃO}

Winnicott adota posição explicitamente contrária ao uso do conceito de pulsão de morte, considerando-o um erro de Freud (WINNICOTT, 1987, p.42).

É essa posição que pretendo abordar aqui. Para isso, procuro comentar os motivos que fizeram Freud propor este conceito e indicar as alternativas que Winnicott apresentou para pensar os problemas aos quais Freud associou a pulsão de morte. Freud propôs esse conceito tendo em vista a procura de explicação para dois conjuntos de fatos: a compulsão à repetição e a agressividade. Delimitarei, aqui, minha análise à compulsão à repetição, deixando a questão da agressividade para outro momento.

\section{A PULSÃO DE MORTE PARA FREUD COMO FUNDAMENTO METAPSICOLÓGICO PARA COMPREENSÃO DA COMPULSÃO À REPETIÇÃO}

No tratamento de neuróticos, Freud notou que os pacientes repetiam, em análise, os modos de relacionamentos afetivos que lhes causavam sofrimento. Nesse quadro de tratamento das neuroses de transferência (histeria, fobia, neurose obsessiva), ele considerou que o aparelho psíquico seria regido pelo princípio do prazer, ou seja, pela busca de obter prazer ou afastar-se da dor. No entanto, sua prática clínica colocou-o ante a uma série de problemas (sadismo, masoquismo, hipocondria, neuroses traumáticas, neuroses de guerra, suicídio do melancólico etc.) que contrariavam a tese de que o psiquismo tem como objetivo básico a busca do prazer. Referindo-se a outro conjunto de fatos clínicos, Freud observou que alguns indivíduos pareciam estar marcados por um "destino demoníaco" (FREUD, 1920, p.292), que os levava a repetir, inúmeras vezes, as mesmas situações traumáticas. Outros, ainda, pareciam reagir de forma contrária à sua cura, piorando ao invés de melhorar, sem nenhum motivo que justificasse esse fato, o que Freud caracterizou como sendo uma "reação terapêutica negativa" (FREUD, 1920, p.292). Este conjunto de fatos clínicos levou-o a reformular sua teoria das pulsões, postulando a existência de outros impulsos básicos para o funcionamento do psiquismo, para além do princípio do prazer. ${ }^{1}$

A sua analogia entre os processos termodinâmicos e o funcionamento do aparelho psíquico, associada à sua consideração de que a vida advém do não vivo, levou-o à suposição de que haveria, no psiquismo, uma tendência básica a encontrar o nível mais baixo de excitação. Sendo assim, Freud supôs uma pulsão cuja "missão" seria conduzir a vida orgânica de volta ao nível zero de excitação,

\footnotetext{
${ }^{1}$ Cf. em Fulgencio (2008, Parte III), um estudo sobre o conceito de pulsão de morte em Freud, bem como uma análise mais detalhada das razões clínicas que levaram Freud a propor este conceito (idem, p.319-322),
} 
ou seja, ao estado inanimado: uma pulsão de morte. ${ }^{2}$ Esse impulso seria, na verdade, a própria essência daquilo que é pulsional. ${ }^{3}$

Ao considerar esse tipo de tendência fundamental, seria possível compreender por que existiriam tantos fenômenos na vida psíquica que ocorreriam à revelia do princípio do prazer; mais ainda, seria possível também reconhecer a presença desses fenômenos na vida cotidiana e no próprio tratamento psicanalítico:

"No inconsciente anímico, de fato, pode-se reconhecer o domínio de uma "compulsão à repetição" emanando das moções pulsionais, que dependem provavelmente da natureza mais íntima das pulsões elas mesmas, e que é suficientemente poderosa para se colocar acima do princípio do prazer, conferindo a certos aspectos da vida da alma um caráter demoníaco, que se manifesta muito claramente nas tendências da criança pequena e que domina uma parte do rumo da psicanálise de pacientes neuróticos." (FREUD, 1919, p.172)

Freud reconheceu explicitamente que sua proposição é uma especulação (1920, p.292), mas uma especulação útil e adequada para organizar e sistematizar os fatos de forma simplificada (cf. FREUD, 1930, p.305). No entanto, duvida da sua própria proposição (FREUD, 1923, p.285 e 1920, p.333), chegando mesmo a comentar que ela se impôs a ele: "com o passar do tempo elas adquiriram tal poder sobre mim que eu não posso mais pensar de outra maneira” (FREUD, 1930, p.305).

Freud toma a situação na qual uma criança repete uma brincadeira com um carretel (denominada por ele brincadeira do Fort-Da), fazendo-o desaparecer e reaparecer, a seu comando, no seu campo de visão, como um modelo para explicar a repetição de uma situação traumática (a mãe desaparece) vivida passivamente. A criança, na brincadeira, revive a cena na qual a mãe desaparece e

\footnotetext{
${ }^{2}$ Para um estudo sobre a natureza e função do conceito de pulsão de morte em Freud, veja, por exemplo, Caropreso \& Simanke (2008) e Olsen \& Koppe (1986).

${ }^{3}$ Freud aplicou o segundo princípio da termodinâmica (no interior de um sistema fechado os diferentes níveis energéticos tendem para a igualdade), por analogia, ao que considerou ser o objetivo último do funcionamento do aparelho psíquico. Esse princípio, também formulável como princípio da constância, aliado às propostas de Gustav Theodor Fechner (que analisam o funcionamento psíquico dentro desta mesma lógica da física termodinâmica) e às concepções de Kant sobre a necessidade de se convencionarem forças como causas incondicionadas dos movimentos na natureza, são as referências básicas de Freud a partir das quais propôs o conceito de Pulsão de Morte, ante os fatos clínicos citados (cf. Fulgencio, 2003 e 2008, uma análise mais detalhada do kantismo de Freud e da origem do conceito de pulsão de morte em Freud). A pulsão de morte, para Freud, é uma especulação sobre um impulso fundamental (de natureza psíquica) que poderia ser suposto como motor causal do princípio da constância e que, em última instância, estaria na base da compulsão à repetição.
} 
reaparece (o carretel representando a mãe), só que, agora, sob o seu controle, de forma ativa (cf. FREUD, 1920, p.285).

Para além da descrição empírica dessa situação (tanto o sumiço da mãe como a brincadeira do Fort-Da), Freud introduz certas metáforas e analogias, buscando uma descrição metapsicológica desses fatos: a situação traumática corresponde a uma excitação (um quantum de energia) que não pôde ser descarregada, permanecendo reprimida (tornada inconsciente), mas que retorna, como algo que exige ser descarregado. A brincadeira, que encena o desaparecer e o aparecer da mãe, visa a repetir uma situação traumática com vistas à descarga de excitação que não pôde ocorrer na vivência que lhe deu origem. A repetição tem como objetivo, em última instância, realizar uma descarga de excitação, diminuindo o nível de tensão no interior do aparelho psíquico. Freud aplica a mesma dinâmica metapsicológica a outros fenômenos, tais como alguns sintomas característicos dos neuróticos de guerra e o denominado “destino demoníaco” (FREUD, 1920, p.292), que leva alguns indivíduos a repetir inúmeras vezes o mesmo tipo de sofrimento. ${ }^{4}$

\section{REITERAÇÕES E CRÍTICAS PÓS-FREUDIANAS À IMPORTÂNCIA DO CONCEITO DE PULSÃO DE MORTE PARA A PSICANÁLISE}

A pulsão de morte pós-Freud foi tanto aceita e reiterada quanto profundamente criticada. Dentre as grandes transformações propostas para o desenvolvimento da psicanálise, representadas aqui por Melanie Klein, Wilfred Bion, Jacques Lacan e Donald Winnicott, há três tipos de atitude quanto a esse conceito: 1) a adesão e aprofundamento dessa perspectiva, tal como fez Klein; 2) a tentativa de substituir esse conceito por outros tipos de metapsicologia, tal como em Bion e Lacan; e 3) a rejeição completa desse conceito, com Winnicott.

Laplanche e Pontalis comentam que muitos psicanalistas consideraram a noção de pulsão de morte como algo inaceitável, e que os fatos clínicos a ela relacionados deveriam ser interpretados sem essa especulação. Para eles, agrupando as perspectivas críticas dos psicanalistas em oposição ao conceito de Freud, há três tipos de objeções: 1) não seria aceitável propor que tudo, no psiquismo, possa ser reduzido às forças pulsionais; 2) não é adequado explicar a gênese da agressividade como sendo, desde sempre, algo que o sujeito imporia aos objetos com

\footnotetext{
${ }^{4}$ Outra maneira de considerar a compulsão à repetição no quadro do pensamento de Freud, complementar à acima comentada (também formulada em termos metapsicológicos), é a suposição de que ela é uma maneira de o Ego conseguir "ligar" uma energia que está "desligada", tendo como objetivo fornecer maior estabilidade ao aparelho psíquico, também de acordo com o princípio de constância. O sentido da repetição é mais uma vez explicado em termos físico-energéticos, por analogia aos sistemas físicos fechados.
} 
os quais se relaciona; 3) seria um erro falar no amor e no ódio (impulsionados pelas pulsões) desde o início das relações objetais; estes sentimentos deveriam ser levados em conta apenas quando houvesse já a possibilidade de reconhecimento de objetos como pertencentes ao mundo exterior (LAPLANCHE \& PONTALIS, 1967, Vocabulário de Psicanálise, verbete "Pulsão de Morte”)

Uma análise detalhada dessas perspectivas críticas certamente também nos levaria a analisar como Bion e Lacan - autores que propuseram novas formulações teóricas para a psicanálise — se afastaram do conceito de pulsão de morte, substituindo-o por outros conceitos, numa nova versão da metapsicologia. Esses dois autores, com diferenças profundas em relação a Freud e também entre si, podem ser reunidos no grupo daqueles que defendem a necessidade da teorização metapsicológica na psicanálise. ${ }^{5}$ Paul-Laurent Assoun (2000), ao analisar os destinos da metapsicologia pós-Freud, classificará Bion e Lacan como autores que reescreveram a metapsicologia freudiana, e Winnicott como um autor que não tem uma metapsicologia.

Poderíamos, para mostrar a atualidade desse debate, citar autores da literatura atual que se posicionaram, e ainda se posicionam, na defesa e elogio da pulsão de morte (GORDON, 1961; GREEN,1995, 2007; LUCAS, 2002; BLANCO, 2005; REEVES, 2007), bem como outros tantos que rejeitam a proficuidade de tal conceito especulativo de Freud (BLACK, 2001; GEYSKENS, 2003; ARMENGOU, 2009). No entanto, há um duplo objetivo aqui: por um lado, aprofundar a perspectiva de análise que mostra Winnicott como um autor que rejeitou a teorização de tipo metapsicológico na psicanálise; por outro, a consequência dessa atitude, mostrando a alternativa de Winnicott para pensar a questão da compulsão à repetição sem apelar para o conceito especulativo de pulsão de morte. Produz-se, dessa forma, uma redescrição dos fatos e das teorias pertinentes ao campo da psicanálise. Assim, Lacan e Bion não precisam participar desta argumentação sobre o destino da pulsão de morte na psicanálise, ainda que, num trabalho mais amplo, devessem ser necessariamente analisados.

No que se refere à Winnicott, sua posição não apresenta ambiguidade alguma. Ele diz, em 1962: “simplesmente não acho válida sua ideia [de Freud] de pulsão de morte" (WINNICOTT, 1965va, p.161). Trata-se, agora, de retomar as críticas gerais que este autor faz ao conceito de pulsão de morte para mostrar qual alternativa propõe para explicar as origens da agressividade e os fenômenos que Freud caracterizou como impulsionados por uma compulsão à repetição.

\footnotetext{
${ }^{5}$ Sobre a natureza e a função da metapsicologia na psicanálise, veja Fulgencio (2003, 2006 e 2008).
} 


\section{CRÍTICAS DE WINNICOTT AO CONCEITO DE PULSÃO DE MORTE}

Para Winnicott, a pulsão de morte é um erro de Freud, uma solução equivocada que foi aprofundada por Melanie Klein. Numa carta a Money-Kyrle, de 1952, ele afirma:

“É uma pena que Melanie tenha feito um esforço tão grande para conciliar sua opinião com a pulsão de vida e de morte, que são talvez o único erro de Freud. Não preciso lembrá-lo que ele tinha dúvidas a esse respeito quando introduziu o conceito pela primeira vez; e também de que o termo pulsão de morte é mal-usado na Sociedade mais do que qualquer outro, sendo empregado no lugar das palavras agressividade ou impulso destrutivo ou ódio, de uma maneira que, tenho certeza, teria horrorizado Freud." (WINNICOTT, 1987, p.37)

Winnicott, reconhecendo o peso que isso significa para Freud, e considerando este conceito de pulsão de morte como inútil e nocivo para a compreensão dos fenômenos de que trata a psicanálise, afirma:

"Para advertir o leitor, devo dizer que nunca fui apaixonado pelo instinto de morte e ficaria feliz em poder aliviar Freud do ônus de carregá-lo para sempre em suas costas de Atlas. Para começar, o desenvolvimento da teoria a partir de um enunciado do fato de que a matéria orgânica tende a retornar ao inorgânico possui peso muito pequeno em termos de lógica. Não há um relacionamento claro entre os dois conjuntos de ideias. Além disso, a biologia nunca ficou feliz com esta parte da metapsicologia, embora, de modo geral, haja lugar para a mutualidade entre ela e a psicanálise ao longo de toda a linha, até chegar ao ponto do instinto de morte." (1989b, p.187)

Ao referir-se à hipótese freudiana de que a vida busca um retorno ao estado de não-vida, Winnicott dirá: "no que diz respeito à psicologia, não significa absolutamente nada, exceto uma afirmação do óbvio. Provavelmente não é verdade nem mesmo na sua forma mais crua e simples" (WINNICOTT, 1988, p.35-36 e 1987, p.35-36, carta de 27 de novembro de 1952, para Money-Kyrle).

Winnicott não considera que a vida advenha da não-vida, mas que o estado de ser advém de um estado anterior de não-ser, que ele também caracteriza como sendo uma solidão essencial (1988, p.153). Recusando a hipótese freudiana, adverte:

“(Mesmo isto [que a matéria orgânica emerge da matéria inorgânica] não é de todo correto, já que o indivíduo desenvolve-se a partir de um ovo que tem sua pré-história em todos os ovos ancestrais, fertilizados desde que a matéria orgânica emergiu do 
inorgânico, há muitos milhões de anos atrás); ao mesmo tempo, do ponto de vista do indivíduo e da experiência individual (que constitui a Psicologia), o indivíduo emerge não do inorgânico, mas da solidão. Este estado surge antes do reconhecimento da dependência, estendendo-se à dependência como ocorrendo em relação a uma confiabilidade absoluta. Este estado é muito anterior ao instinto, e mais longínquo ainda da capacidade de sentir culpa." (WINNICOTT, 1988, p.155)

Winnicott lamenta que Klein tenha se apoiado nessa noção, "porque ela confunde tudo” (WINNICOTT, 1987, p.35-36); é uma proposição metapsicológica que cria, segundo ele, uma "aparência de compreensão onde tal compreensão não existe" (Idem, p.51).

Avaliando o conceito de pulsão de morte como um erro de Freud e, portanto, um engano reiterado por Melanie Klein, Winnicott proporá alternativas para pensar tanto os fenômenos agrupados por Freud como movidos por uma compulsão à repetição quanto o problema de saber qual é a origem da agressividade e da destrutividade no ser humano. Essas alternativas dependerão da compreensão da imaturidade do bebê e de sua relação de dependência ao ambiente no início do processo de amadurecimento.

\section{ALTERNATIVA WINNICOTTIANA PARA A COMPREENSÃO DA COMPULSÃO Ȧ REPETIÇÃO SEM O CONCEITO DE PULSÃO DE MORTE}

Winnicott usa a expressão "compulsão à repetição” no seu diálogo com outros psicanalistas, e não propriamente quando está desenvolvendo suas próprias concepções. Num comentário ao livro de Fairbairn, ele se refere à compulsão à repetição como uma necessidade do paciente de retomar a situação penosa em condições de poder integrá-la na sua área de controle:

“É possível obter algo do trabalho de Fairbairn sobre os sonhos, considerando o relacionamento de seu conceito de introjeção do objeto mau ao trabalho de Freud sobre a compulsão à repetição. Se o objeto mau introjetado (a fim de ser coagido ou controlado) constitui uma experiência penosa, isto é, algo percebido, mas não tolerado, então a experiência introjetada repetidamente clama por atenção e dá origem a um tipo específico de sonho. O conceito de compulsão à repetição nos faz atravessar o período que precisamos para a compreensão de que, para chegar atrás da compulsão à repetição, o paciente tem de redescobrir a situação penosa externa tal como foi originalmente percebida, embora na ocasião não pudesse ser tolerada como um fenômeno situado fora do controle onipotente." (WINNICOTT, 1953, p.317-318) 
É fundamental salientar que, nessa resenha sobre o livro Psychoanalytic studies of the psychoanalysis (1953), de Fairbairn, escrita em parceria com Masud Khan, Winnicott critica Fairbairn por não considerar adequadamente a imaturidade do bebê, o qual não teria a possibilidade de relacionar-se com objetos bons ou maus. Para Winnicott, isso só seria possível se cuidados suficientemente bons tivessem sido dados na primeira infância, levando a criança à maturidade, que caracteriza a integração da pessoa como uma unidade e a possibilidade de estabelecer relacionamentos também com pessoas inteiras.

Diz Winnicott, enfatizando sua crítica: "Fairbairn começa por um bebê que é um ser humano total, um ser que experiencia a relação com o seio como um objeto separado, um objeto que experienciou e a respeito do qual tem ideias complicadas" (1953, p.318). O autor avalia que Fairbairn se refere à situação inicial, na qual há um bebê que não pode, ainda, diferenciar entre si-mesmo e os objetos (1953, p.320). É por isso que ele diz ser necessário compreender o que ocorre antes do período em que o bebê alcançou a possibilidade de estabelecer relações com objetos (quando será possível diferenciar entre um dentro e um fora, entre Eu e não Eu), bem antes de a criança alcançar o estágio em que se sente como uma pessoa inteira que se relaciona com os outros como pessoas inteiras. É a compreensão desse período que nos possibilitará entender o que Winnicott quer dizer com colocar a situação penosa dentro do controle onipotente.

O período do controle onipotente diz respeito às fases iniciais, quando, como não existe, do ponto de vista do bebê, uma realidade não-self (1988, cap. IV e V), este vive a experiência (quando o ambiente se adapta adequadamente) de que, das suas necessidades, advém aquilo que as satisfaz, como um derivado natural destas. Decerto, do ponto de vista do observador, vemos o ambiente levando objetos e cuidados até o bebê; sabemos também que, considerando a sua extrema imaturidade, o bebê não sabe o que pode derivar de suas necessidades, nem quais são elas.

Do ponto de vista do observador, o mundo é oferecido ao bebê; do ponto de vista do bebê, ele é criado. A esse respeito, afirma Winnicott: "A adaptação da mãe às necessidades do bebê, quando suficientemente boa, dá a este a ilusão de que existe uma realidade externa correspondente à sua própria capacidade de criar. Em outras palavras, ocorre uma sobreposição entre o que a mãe supre e o que a criança poderia conceber" (1955, p.27).

Essa é a área do controle onipotente para a qual é necessário voltar, porque é preciso retornar a um modo de relação com o mundo no qual é o self que se afirma enquanto tal, como uma ação que advém dele, e não como uma reação. É esse ponto de partida básico, que reitera o ser e dá continuidade a ele, que alguns pacientes procuram. Mas este ponto corresponde também a um modo de relação de dependência do ambiente. 
Trata-se, pois, não tanto de procurar uma descarga, mas um ponto com base no qual o self se afirma. Isso se dá de três modos: 1) sustentado pelo ambiente (quando o ambiente fornece ao self a adaptação de que necessita), estabelecendo um modo de relação com a realidade caracterizada pelo relacionamento com objetos subjetivos; 2) no modo de relacionamento marcado pelo brincar e pela transicionalidade, que mantém esse fundo subjetivo (no qual o si-mesmo cria o mundo) e, ao mesmo tempo, fornece uma exterioridade, constituindo o paradoxo que caracteriza os objetos transicionais (o objeto é criado e encontrado ao mesmo tempo); e 3) no modo de relação com a realidade percebida objetivamente, no qual, para que essa realidade não seja vivida como uma pressão para a reação e adaptabilidade do si-mesmo, este último a sente como algo com o qual pode contribuir e partilhar.

Winnicott considera que é na ação de brincar (como atividade que reuniria estes três modos de relação com a realidade: subjetivo, transicional, externo) que o indivíduo descobre a si-mesmo: “É no brincar, e somente no brincar, que o indivíduo, criança ou adulto, pode ser criativo e utilizar sua personalidade integral; e é somente sendo criativo que o indivíduo descobre o eu (self)" (1971, p.80).

A compreensão da postura de Winnicott, no que se refere à necessidade de retomar (corrigir) as experiências passadas, pode mostrar como ele concebe essa necessidade de uma maneira que difere da suposição metapsicológica de uma compulsão à repetição. Ao falar sobre alguns pacientes que tiveram falhas ambientais em momentos em que não tinham condições (de amadurecimento) para abarcar todos os acontecimentos dentro da sua área de domínio, Winnicott comenta:

\footnotetext{
"Segundo minha experiência, existem momentos em que se precisa dizer a um paciente que o colapso, do qual o medo destrói-lhe a vida, já aconteceu. Trata-se de um fato que se carrega consigo, escondido no inconsciente. [...] Neste contexto especial, o inconsciente quer dizer que a integração do ego não é capaz de abranger algo. O ego é imaturo demais para reunir todos os fenômenos dentro da área da onipotência pessoal.” (1974, p.73)
}

Nessas condições, o que foi vivido não foi experienciado, ficando, por assim dizer, "guardado” ou “congelado”, à espera de melhores condições ambientais e pessoais para ser, então, de fato experienciado e, então, integrado à personalidade. Para fornecer um conteúdo mais intuitivo a tal fato, Winnicott faz uma analogia com o que ocorre entre o bulbo e a flor que dele se origina: 
“Tentando encontrar uma analogia, vi um bulbo de jacinto a ser plantado em uma tigela. Pensei: há um odor maravilhoso trancado naquele bulbo, embora soubesse, naturalmente, não existir um lugar no bulbo em que o odor se ache trancado. A dissecação do bulbo não proporcionaria, a quem a fizesse, a experiência de uma fragrância de jacinto, se o lugar apropriado estivesse por ser alcançado. Apesar disso, existe no bulbo um potencial que acabará se tornando um perfume característico, quando a flor se abrir. Isto não passa de uma analogia, mas poderia transmitir um retrato do que estou tentando enunciar." (1989b, p.99-100)

O descongelamento da situação da falha ambiental corresponde ao descongelamento das defesas e ao retorno a uma fase anterior à da falha, para que o amadurecimento possa ser retomado.

A necessidade de integração (de colocar a experiência na área de controle do self) pode, então, levar esse indivíduo a procurar justamente aquelas situações que retomam as mesmas condições traumáticas vividas no passado, produzindo uma repetição, cujo sentido diz respeito à tentativa de colocar o que foi vivido dentro da sua área de controle onipotente, ou seja, de poder experienciar aquilo que está cindido nele, integrando esse não-vivido. Assim, tornar-se-ia possível a continuidade do amadurecimento, a sua continuidade de ser. Mesmo que seja doloroso, o que foi vivido não pode aniquilar o indivíduo, ou a área de ilusão necessária ao indivíduo.

Não se trata propriamente de voltar à situação traumática, mas ao momento anterior ao trauma, em que as defesas em relação a essa situação ainda não tinham sido erguidas (ou seja, voltar a um momento em que se desfazem as defesas), para, então, retomar o processo de amadurecimento a partir deste ponto.

Mas, para que isso ocorra, o paciente precisará regredir ao momento anterior a esse colapso da situação traumática, quando ele era sustentado pelo ambiente, o que lhe dava uma ilusão de onipotência. Esse momento é atualizado nas suas relações (eventualmente na sua análise) e, com base nelas, a repetição (procurada) da mesma situação de colapso pode, então, ser vivida noutras condições, ou seja, pode ser experienciada sem que a pessoa seja aniquilada. Sendo assim, o indivíduo pode, então, ser integrado, e seu amadurecimento prosseguir. Por um lado, essa regressão diz respeito ao retorno a uma situação de dependência, atualizada com o analista; por outro, à necessidade de retomar o momento anterior ao que as defesas foram erguidas. Sobre isso, explicita Winnicott:

“Tudo isso pode ser muito claramente demonstrado no tratamento analítico, desde que sejamos capazes de seguir o paciente para trás no desenvolvimento emocional tanto quanto ele precisa ir, pela regressão à dependência, a fim de alcançar o mo- 
mento anterior àquele em que as intrusões tornaram-se múltiplas e impossíveis de controlar.” (WINNICOTT, 1958, p.276)

Abandonada a pulsão de morte, recusado todo tipo de especulação metapsicológica, Winnicott ofereceu uma alternativa para pensar a compulsão à repetição como uma busca de si-mesmo que não é propriamente procurada num interior, mas num ambiente e na relação inter-humana. Nesse sentido, é interessante retomar um comentário de Phillips: “Em Winnicott, o homem só pode encontrar a si-mesmo em sua relação com os outros, e na independência conseguida através do reconhecimento da dependência”. (PHILLIPS, 2007, p.29)

Quando há partes cindidas na personalidade, quando há situações que foram vividas e não experienciadas, a necessidade de ser leva o homem a procurar retomar seu processo de amadurecimento no ponto em que ele foi interrompido, nas condições em que foi interrompido para, então, dar continuidade a seu ser.

Recebido em 23/10/2009. Aprovado em 6/7/2010.

\section{REFERÊNCIAS}

ARMENGOU, F. G.-C. (2009) The death drive: Conceptual analysis and relevance in the Spanish psychoanalytic community, The International Journal of Psychoanalysis, 90 (2), 263-289.

ASSOUN, P.-L. (2000) La métapsychologie. Paris: PUF.

BLACK, D. M. (2001) Mapping a detour: why did Freud speak of a death drive?, British Journal of Psychotherapy, 18(2), 185-198.

BLANCO, I. M. (2005) The four antinomies of the death instinct, The International Journal of Psychoanalysis, 86(5), 1463-1476.

CAROPRESO, F., \& SIMANKE, R. T. (2008) Life and death in Freudian metapsychology: A reappraisal of the second instinctual dualism, The International Journal of Psychoanalysis, 89(5), 977-992.

FREUD, S. (1996) Oeuvres completes. Psychanalyse. Paris: PUF.

(1919) "L'inquiétant", v.15, p.147-188.

(1920) “Au-delà du principe du plaisir", v.15, p.273-338.

(1923) "Le moi et le ça”, v.16, p.255-301.

(1930) "Le malaise dans la cultura", v.18, p.245-333.

FULGENCIO, L. (2003) As especulações metapsicológicas de Freud, Revista de Filosofia e Psicanálise Natureza Humana, 5(1), 127-164.

(2006) Winnicott e uma psicanálise sem metapsicologia, Revista de Filosofia e Psicanálise Natureza Humana, 8(Especial 1), 401-420. (2008) O método especulativo em Freud. São Paulo: Educ.

GEYSKENS, T. (2003) Imre Hermann's Freudian theory of attachment. The International Journal of Psychoanalysis, 84(6), 1517-1529. 
GORDON, R. (1961) The death instinct and its relation to the Self, The Journal of Analytical Psychology, 6(2), 119-135.

GREEN, A. (1995) Propédeutique. La métapsychologie revisitée. Seyssel: Champ Vallon.

(2007) Pourquoi les pulsions de destruction ou de mort? Paris: Panamá.

LAPLANCHE, J. \& PONTALIS, J.-B. (1967). Vocabulaire de psychanalyse. Paris: PUF.

LUCAS, R. (2002) The concept of the death instinct: a clinical viewpoint, British Journal of Psychotherapy, 18(4), 568-570.

OLSEN, O. A., \& KOPPE, S. (1986) Problems in Freud's metapsychology, Scandinavian Journal of Psychology, 27(1), 163-174.

PHILlIPS, A. (2007) Winnicott. São Paulo: Ideias \& Letras.

REEVES, C. (2007) The mantle of Freud: was the use of an object Winnicott's todestrieb, British Journal of Psychotherapy, 23(3), 365-382.

WINNICOTT, D. W. (1987b/1990) O gesto espontâneo. São Paulo: Martins Fontes.

(1988/1990) Natureza humana. Rio de Janeiro: Imago.

(1994) Explorações psicanalíticas. Porto Alegre: Artes Médicas.

(1953) "Resenha de Psychoanalytic Studies of the Personality, de W. R. D. Fairbairn”, p.316-322.

(1974) "O medo do colapso", p.70-76.

(1989a) "Psiconeurose na infância”, p.53-58.

(1989b) "O uso do objeto no contexto de Moisés e o monoteísmo", p.171-177.

(2000) Da pediatria à psicanálise. Rio de Janeiro: Imago.

(1955) "A posição depressiva no desenvolvimento emocional normal", p.355-373.

(1958) "Memórias do nascimento, trauma do nascimento e ansiedade”, p.254-276.

(1965) “Enfoque pessoal da contribuição kleiniana”, p.156-162.

"O brincar: a atividade criativa e a busca do eu (self)", in (1975) O brincar \& a realidade. Rio de Janeiro: Imago.

(1983) O ambiente e os processos de maturação. Porto Alegre: Art-

med.

Leopoldo Fulgencio

leopoldo.fulgencio@gmail.com 